\title{
AN INQUIRY INTO THE RAMSEY-Hotelling CONNECTION
}

Full reference:

GASPARD, Marion and Missemer, Antoine. 2019. "An Inquiry into the Ramsey-Hotelling Connection". European Journal of the History of Economic Thought, 26(2), 352-379.

[https://doi.org/10.1080/09672567.2019.1576059]

The pagination of the published version is indicated in the margin.

\begin{abstract}
Ramsey's 1928 paper on saving and Hotelling's 1931 article on exhaustible resources are considered to be two seminal contributions in economic dynamics. They have been associated because of their temporal proximity, use of the calculus of variations, and because of Hotelling's citation of Ramsey. This connection however needs to be precisely investigated and characterized. On the basis of archival material, this paper shows that, on the interpersonal and theoretical ground, the connection is quite thin, but that significant parallels are found in Ramsey's and Hotelling's expectations with mathematical economics for the progress of science and for informing public decision.
\end{abstract}

Keywords: Ramsey; Hotelling; mathematical economics; dynamics; intertemporal distribution; saving; exhaustible resources; history of economic thought

\footnotetext{
* [In 2019] Triangle, University of Lyon 2, ISH 14 av. Berthelot, F-69363, Lyon Cedex 7. E-mail: marion.gaspard@univ-lyon2.fr $\dagger$ [In 2019] CNRS, CIRED Paris - Centre international de recherche sur l'environnement et le développement (UMR 8568 CNRS/ENPC/EHESS/AgroParisTech/CIRAD), 45bis avenue de la Belle Gabrielle, F-94736 Nogent-sur-Marne Cedex. E-mail: missemer@centre-cired.fr
} 


\section{Introduction}

Frank P. Ramsey and Harold Hotelling provided early and seminal contributions in the field of mathematical economic dynamics. Ramsey's 1928 paper “A Mathematical Theory of Saving", published in the Economic Journal, and Hotelling's 1931 article "The Economics of Exhaustible Resources", published in the Journal of Political Economy, have sometimes been associated to date the beginning of "optimal growth theory" (Arrow 2009, 13). Both articles were written at the turn of the 1930s, both were concerned by intertemporal choice issues, both used the calculus of variations. ${ }^{1}$ In his paper, Hotelling moreover cited Ramsey (1931a, 145). These various points led commentators to gather Ramsey and Hotelling in the same early tradition of modern mathematical economics (Kula 1996, 80-81; Michel 1990; Read 2016, 171-172; Weitzman 2003, 30), even to talk about a "Ramsey-Hotelling connection" (Erreygers 2009 , 265f), with great proximity, even continuity, between the two authors (Arrow and Kurz 1970, 26; Duarte 2009b; Kamien 1987; Kamien and Schwartz 1991, 3). In the New Palgrave, Bromley (2008) corroborates this close relationship.

Historically speaking, the Ramsey-Hotelling connection is anything but obvious. Frank P. Ramsey and Harold Hotelling were contemporaries, the former being born in 1903, and the latter in 1895. But Ramsey died in 1930, so his career was very short. Hotelling experienced a longer life, until his death in 1973. While Ramsey grew in England and was trained at Cambridge, Hotelling came from Minnesota, and made his whole career in the United States (apart from temporary visiting stays in foreign countries). They evolved in different intellectual contexts, had different teachers within different university traditions. Obviously, since he genuinely quoted it, Hotelling knew Ramsey's

\footnotetext{
${ }^{1}$ The calculus of variations is a technique of integrals optimization, coming from pure mathematics and physics. After some developments from the seventeenth to the nineteenth centuries, mathematicians particularly investigated the calculus of variations in the beginning of the twentieth century (Bolza 1904; Hadamard 1910; Hancock 1904; Hilbert 1900; Kneser 1900; Mayer 1905). See also Goldstine 1980.
}

work on saving. But there is no evidence that the opposite was true.

According to Arrow (1974, 1103; 1980, 1987, 670), Hotelling (who was his PhD supervisor) intended to publish his contribution on exhaustible resources in the Economic Journal. Keynes and McGregor, editors-in-chief of the journal at that time, would have rejected it because of mathematical complexity - a surprising argument since Ramsey's 1928 paper was very complex too. Arrow (1980, 637) suggests that Keynes probably favored Ramsey because of his Cambridge (UK) affiliation. In his reconstruction of Hotelling's career, Darnell $(1990,13)$ relates the story and expresses his own surprise about the asymmetric consideration of the two papers by the Economic Journal. ${ }^{2}$ On the basis of a similar episode for one of Harrod's papers, Gans and Shepherd (1994, 174-175) suggest that Ramsey could have been one of the reviewers of Hotelling's 1931 paper. At first sight the story is plausible. Hotelling had just published "Stability in Competition" (1929) in the Economic Journal and may have been encouraged to submit his contribution to a journal that had already published papers on dynamic issues; and Keynes indeed regularly asked Ramsey's opinion on submitted papers. Actually, apart from Arrow's testimony, there is no evidence that Hotelling really submitted his 1931 paper to the Economic Journal. Hotelling saved most of his notes, personal documents and memos, which are today gathered at the Rare Book and Manuscript Library of Columbia University, and a careful examination of these archives does not show any trace of such a submission. There is nothing in Keynes' archival material at Cambridge University either. The editorial correspondence of Keynes does not mention any reference to Ramsey with respect to Hotelling. Moreover, the chronology seems to contradict the idea that Ramsey could have commented on Hotelling's 1931 paper: in July 1930, in a letter to R. A. Fisher, Hotelling wrote that he had left a statistical project aside "for a few weeks $[\ldots]$ to finish a paper on "The Economics of Exhaustible Assets"”, ${ }^{3}$. This means

\footnotetext{
${ }^{2}$ See also Darnell 1988, 60; Duarte 2009b, $163 \mathrm{f}$.

${ }^{3}$ Letter from Hotelling to Fisher, July 23rd, 1930 (RAFP, digitized version online).
} 
that the 1931 paper was not finished for submission in the summer of 1930. Ramsey died in January 1930.

As a result, as far as the Ramsey-Hotelling connection is concerned, if there is any direct explicit connection between the two authors, it must be Hotelling reading Ramsey, rather than the other way round. But the link between Ramsey's 1928 paper on optimal saving and Hotelling's 1931 paper on exhaustible resources raises questions beyond this potential direct influence. Are there substantial reasons to connect the two papers apart from similar topics related to dynamics, the calculus of variations and a short citation? What kinds of parallels can further be drawn? In particular, what may be said about the role of mathematics in both Ramsey's and Hotelling's research projects?

On the basis of published and unpublished material, this paper consists of an historical and methodological inquiry to characterize and analyze the presumed Ramsey-Hotelling connection. Section 1 briefly recalls the intellectual trajectory of Ramsey until the end of the 1920 s and his contribution on optimal saving. Section 2 reconstructs the successive steps of elaboration of Hotelling's article on exhaustible resources, by questioning the impact of Ramsey, and by qualifying the usual relations depicted in the literature. Section 3 explores another way of investigating the connection between Ramsey and Hotelling, from their shared expectations with mathematics. Some concluding remarks follow.

\section{Ramsey and saving}

\subsection{Mathematics, logicism and economics}

Frank P. Ramsey was born at the very beginning of the twentieth century in Cambridge (UK). ${ }^{4}$ His father, Arthur Stanley Ramsey, taught applied mathematics at Magdalene College. Ramsey basically learnt mathematics with his father, and through the lessons of Clement Vavasor Durell during secondary school in Winchester. His diary reveals that he also read some mathematics and mechanics

\footnotetext{
${ }^{4}$ Ramsey's biography is well documented (Duarte 2009a; 2016; Paul 2012; Sahlin 1990; Taylor 2006).
}

textbooks recommended by his father and by Durell (Paul 2012, 47). It is probably at this moment that he became familiar with the calculus of variations. ${ }^{5}$ After secondary school, Ramsey studied mathematics at Trinity College, Cambridge. He was elected fellow of King's College in 1924, and became a lecturer in 1926.

On the fringe of his mathematical curriculum, he frequented many of the interdisciplinary circles flourishing in Cambridge. That gave him occasions to express his growing interest in analytical philosophy on the one hand, and in social sciences on the other. In particular, Ramsey was well integrated in the Heretics Society and in the Moral Sciences Club, before becoming a member of the Apostles Society. Bertrand Russell, George Edward Moore and John Maynard Keynes were members of these three societies.

Ramsey started his academic works with the translation (with Charles K. Ogden) of Wittgenstein's Tractatus Logico-Philosophicus (1922) and with a few contributions to the logicist program developed by Russell since the beginning of the century (Russell 1903; Russell and Whitehead 1910). ${ }^{6}$ Ramsey's first papers "The Foundations of Mathematics" (1925a), "Universals" (1925b) and "Mathematical Logic" (1926a) belong to Russell's global project of refoundation of mathematics on logical grounds. ${ }^{7}$ Through a criticism of Keynes' Treatise on Probability, and the establishment of his own theory of subjective probability in "Truth and Probability" (Ramsey 1926b), Ramsey finally emancipated from the logical atomism of his first papers, and turned to the construction of his own philosophical system: a pragmatist theory of

\footnotetext{
${ }^{5}$ Margaret Paul, Ramsey's sister, relates $(2012,47)$ that Ramsey assisted to his father's 1918 lectures on dynamics, and that he read "Besant and Ramsey, dynamics" in January 1920 (probably Arthur's 1913 Treatise on Hydromechanics, part II). This textbook adopts a pure theoretical point of view and presents Euler's and Laplace's methods to deal with problems of fluid dynamics in various conditions.

${ }^{6}$ Ramsey listened to Russell's lectures in Cambridge and London in 1920-1921, and had occasions to discuss some elements of the Principia Mathematica with him (Paul 2012, 81, 111, 155).

${ }^{7}$ Mellor (1990, xiii) considers "The Foundations of Mathematics" (Ramsey, 1925a) as "the culmination of the logicist programme". On Ramsey and logicism, see also Sahlin 1990.
} 
knowledge (Gaspard 2014; Sahlin 1990). ${ }^{8}$ From 1927 to 1930, a series of essays such as "Facts and Propositions" (Ramsey 1927a), "Theories" (Ramsey 1929a) or "General Propositions and Causality" (Ramsey 1929b) paved the way for an ambitious theory of truth, and for the book $O n$ the Nature of Truth Ramsey was elaborating when he died. ${ }^{9}$

Ramsey's personal interest for economic and social issues started at the beginning of the 1920s, in his first presentations at the University Socialist Society about Guild and Fabian socialism, and about Major Douglas' credit theory (Ramsey 1922). He already knew some basics in economics at the time, through his reading of Mill, Marx, Webb, Hobson and Marshall during his Winchester years (Paul $2012,50,55)$. At the turn of the 1920 s, Ramsey entered economics by searching for the means to reduce poverty and inequalities (Gaspard 2003), by thinking about the best way to organize production (Ramsey 1923), and by directly addressing the theoretical debates and methods of the discipline. ${ }^{10}$ From an institutional point of view, Keynes played a decisive part in Ramsey's position at King's College as well as in introducing him to several figures of Cambridge economic theory, including Sraffa, Harrod and Pigou. As mentioned, Keynes was also the editor of the two papers Ramsey published in the Economic Journal (Ramsey 1927b, 1928). ${ }^{11}$

\footnotetext{
${ }^{8}$ Logical atomism, as developed by Russell (1914) and Wittgenstein (1922), focused on the conditions of knowledge. It intended to warrant that knowledge was based on logical compositions of so-called atomic (or elementary) propositions. Atomic propositions were supposed to express atomic facts, described as ultimate and immediate elements of knowledge, independent from each other. Atomic propositions were true or false, by virtue of the truth of the fact they expressed.

${ }^{9}$ The manuscript of this on-going work may be consulted in Ramsey papers (digitized version online).

${ }^{10}$ Ramsey states (1919, quoted by Paul 2012, 67): "The destruction of the wage fund theory is comparable to Galileo's discovery of acceleration. Other parts are like pure mathematics; the question of whether utility or cost of production governs value though extraordinary interesting, seems no more useful than the theory of infinite series. But no doubt the invention of Cartesian Coordinates seemed equally useless at first".

${ }^{11}$ According to the index cards of the John Maynard Keynes's Papers (JMKP), no editorial correspondence survived on Ramsey's paper on taxation (1927b). In contrast, a set of letters, dated July 1928 (JMKP, Box EJ,
}

These two essays were directly connected with, and both inspired by Pigou's economics (Duarte 2009a, 2016; Gaspard 2003, 2005). ${ }^{12}$

In "A Contribution to the Theory of Taxation" (1927b), Ramsey tackles a problem suggested by Pigou: What should be a taxation system allowing to minimize the loss in total social welfare? At the end of his argument, establishing rules to tax goods, Ramsey wonders if saving should also be taxed, but he remarks that answering the question requires a more precise analysis of saving, and a dynamic theory of income (Ramsey 1927b, 59). The issue at stake in Ramsey's 1928 paper may also be associated with Pigou's reflections on individual and social welfare. In the first edition of The Economics of Welfare, Pigou indeed underlines that, because of individuals' defective "telescopic faculties" $(1920,25)$ (i.e. their "irrational" (26) tendency to discount future utilities), capital accumulation may reveal insufficient for warranting a maximum of (intertemporal) "aggregate amount of economic satisfaction" (26). Pigou also notes that the limited character of human life (26) favors present consumption, since (future) "satisfactions due to labor or savings are not necessary enjoyed by the person to whose efforts they are due" (26). Lacks of investment and overexploitation of natural resources are the indications that the "State should protect the interest of the future in some degree" (28). However, concerning the lack of investment, Collard $(1996,596)$ establishes that Pigou (1920, 630-631) hesitated to clearly defend a pro-saving fiscal system, because of potential contradictory effects on economic welfare: encouraging saving may increase intertemporal welfare but also income inequalities, which would threaten total

Folder 1-3), testifies that Keynes carefully read Ramsey's paper on optimal saving. He asked for clarification, offered an intuitive formulation of the optimal saving rule in the context of zero discounting, and discussed Ramsey's assumption of a constant discount rate. Ramsey changed the manuscript, following the requirements, and mentioning Keynes' intuitive result in main text. $\mathrm{He}$ however considered that introducing a variable discount rate would bring only "manipulative interest" (Ramsey in Keynes $1983,788)$. Both sides of the correspondence may be found in Keynes (1983, 784-789).

${ }^{12}$ Duarte (2009a) extensively discusses the possible impact of Ramsey's results on Pigou's work. 
welfare because of decreasing marginal utility.

\subsection{Ramsey's mathematical theory of saving}

Ramsey's 1928 paper starts with the following question: "How much of its income should a nation save?" (543). The argument starts with the establishment of an optimal saving rule for a "nation" obeying the utilitarian precept of no discounting. ${ }^{13}$ A constant population nation is endowed with an infinite time horizon and an unchanged net utility function $\mathrm{U}(\mathrm{x}(\mathrm{t}))-\mathrm{V}(\mathrm{a}(\mathrm{t}))$ with aggregate consumption ( $\mathrm{x}$ ) and labor (a) as arguments. National saving is the condition of capital accumulation $\dot{\mathrm{c}}(\mathrm{t})$; aggregate production (and income) is represented as a result of a production function $\mathrm{f}(\mathrm{a}(\mathrm{t}), \mathrm{c}(\mathrm{t}))$ with decreasing returns for capital (c) and labor (a). Ramsey defines a collective objective, called "Bliss" $(1928,545)$ (B), corresponding either to the satiation level of utility (enjoyed forever), or to the "maximum possible rate of enjoyment" (545), obtained when net capital return turns to zero. With the principle of no discount for future utilities, the optimal rate of saving (maximizing intertemporal utility) should obey the Keynes-Ramsey's rule: at each date, "the rate of saving multiplied by the marginal utility of money should always be equal to the amount by which the total net rate of enjoyment of utility falls short of the maximum possible rate of enjoyment" $(1928,543)$ :

$$
\dot{\mathrm{c}}=\frac{\mathrm{B}-(\mathrm{U}(\mathrm{x})-\mathrm{V}(\mathrm{a}))}{\mathrm{u}(\mathrm{x})} .
$$

Once the rule is stated for a nation with infinite life expectancy, no discounting, and decreasing returns, Ramsey proposes a series of variations (see Attanasio 2015; Gaspard 2003, 415-417; 2005), to adapt the rule to different theoretical case studies: optimal saving for an individual (with finite lifetime) indifferent to his heirs; optimal saving for an individual leaving some capital to his heirs; introduction of a positive and constant discount rate. He discusses

\footnotetext{
${ }^{13}$ When studying the optimal national saving rule, Ramsey defines discounting as an "ethically indefensible" practice, arising "from the poverty of our imagination" (Ramsey $1928,543)$.
}

the determination of the interest rate, and finally concludes by considering classes of individuals (finite life) and "families" (infinite life) endowed with different discount rates. Ramsey's 1928 paper therefore goes far beyond the solely establishment of a rule, providing a sophisticated analysis of intertemporal choices. It extensively examines the practice of discounting and its implications for individual and collective welfare, and eventually, for economic policy.

After Pigou, Ramsey was particularly interested in the design of public policies through fiscal instruments. He did not succeed in introducing taxation in his 1928 analysis in a way sufficiently convincing for him (Ramsey in Keynes 1983, 784), and he finally renounced to publish his original section on the subject (Gaspard 2005, 3; Duarte 2009a, 463). ${ }^{14}$ He was nevertheless satisfied with the published version, already enriched by several variations around the basic rule, and offering "simple results of sufficient generality to be interesting and yet not obvious" (Ramsey in Keynes 1983, 784).

\section{Hotelling and exhaustible resources}

\subsection{Mathematics, economics and statistics}

As a student, Hotelling started with journalism. ${ }^{15}$ Even if he did not participate in the fights, the First World War disturbed his student career. When he came back to his journalism program, new courses, including economics, had been introduced. Even if Hotelling has been sometimes depicted as a mathematician who came to economics (Samuelson 1960, 21), it is noteworthy that he heard about economics before graduating in mathematics. ${ }^{16}$ Journalism was not totally convincing: Hotelling's interests were "in research of deeper sorts than those leading to a steady flow of new items" (Hotelling 1948, 17). Encouraged by Eric

\footnotetext{
${ }^{14}$ This section has been published by Duarte (see Ramsey 2009).

${ }^{15}$ Hotelling's biography can be found in Darnell (1988, 1990), with information mostly coming from autobiographical material (Hotelling 1948, 1963). See also Levene 1974; Smith 1978.

${ }^{16}$ In his autobiography, he even indicates that he studied mathematics to improve his abilities in economics (1948, 17, 20). See also Darnell $(1990,4)$.
} 
Temple Bell, he decided to study mathematics and he obtained his master's degree in 1921. At that time he became accustomed to various mathematical tools, including the calculus of variations. $^{17}$

After graduating, Hotelling tried to get into an economics program at Columbia University, but he was refused and finally joined Princeton to make a $\mathrm{PhD}$ in mathematics. He came to Princeton with the hope to learn mathematical economics and statistics there, but was disappointed again, finding "that nobody in the Princeton mathematics department had ever heard of either subject" (Hotelling 1963, 4). His $\mathrm{PhD}$ dissertation, under the supervision of Oswald Veblen, was therefore about topology (analysis situs) and explored the properties and classifications of figures supposed to be invariant under continuous transformations (Hotelling 1925c). ${ }^{18}$ In March 1924, a fellowship at the Food Research Institute (FRI) in Stanford finally gave him the institutional conditions to develop the research he was expecting. ${ }^{19}$ His interest in statistics began with a work on correlations (Hotelling 1925d, 1926b) but also on the "logical foundations of statistical inference". ${ }^{20}$ Hotelling's fellowship contract also included collaborations with the mathematics and economics departments.

From 1923 onwards, Hotelling made his first extensive contributions in mathematical economics, mobilizing functional analysis rather than topology or statistics. He regularly visited the meetings of the American mathematical society (AMS), where he probably met the mathematician Griffith C. Evans (Darnell 1990, 12). ${ }^{21}$ In December 1924, Hotelling sent his first

\footnotetext{
${ }^{17}$ Crabbé (1986, 2) and Darnell (1990, 4f) suggest that Hotelling could have heard about the calculus of variations during a summer school in Chicago in 1920. Crabbé (1986, 3) also reports a letter to Coffey (dated Sept. 11th, 1964) in which Hotelling indicates that he learnt "advanced portions of the subject [ ... ] in J. Hadamard, Calculus of Variations".

${ }^{18}$ Some generalized results in topology were published a few months later (Hotelling 1926a).

${ }^{19}$ Letter from Alsberg to Hotelling, March 3rd, 1924 (HHP, Box 6, Folder 'Wallis-Fry').

${ }^{20}$ Monthly report from Hotelling to the directors of the Food Research Institute, April 3rd, 1925 (HHP, Box 41, Folder 'Agriculture III').

${ }^{21}$ In the $1920 \mathrm{~s}$, Evans, who contributed to functional analysis (Morrey 1983), had the project to improve the theory of production, through the introduction of price
}

economic paper to the Journal of the American Statistical Association. It was about depreciation, and designed to complete James S. Taylor's 1923 proposal about the optimal path of depreciation charges during the lifetime of a machine. Hotelling's analytical added value considering continuity rather than discretion in time - gave him some reputation among economists (Darnell 1990, 9-10). Some potential extensions appear in that first paper, such as the consideration of mine exploitation (Hotelling 1925a, 352), and the use of functional maxima "for hedonistic and eudaemonistic (sic) ethical theories" (352).

\subsection{Theory of mine economics, drafts and notes (1924-1925)}

In the lineage of his work on depreciation, Hotelling started investigating the issue of exhaustible resources. He presented his first intuitions on the subject during a $10 \mathrm{~min}$. talk on December 26th, 1924 at an AMS meeting in Chicago. ${ }^{22}$ The talk consisted of four parts, including two on exhaustible assets (under competition or monopoly). His notes for the conference explore how to introduce the calculus of variations, "this rather abstruse branch of mathematics" for defining "the most profitable rate of exploiting a mine, when demand is elastic". ${ }^{23}$ Hotelling refers to Evans's equations of demand, considers an integral of profits with constant discount rate, and introduces a limited amount of reserves exploited by competing owners, without totally solving the problem. ${ }^{24}$

variations in demand functions (Evans 1922, 1924, 1925). He was an advocator of the calculus of variations, whose relation with economics was considered as "not accidental" $(1925,94)$. On the mathematical tradition of economic analysis coming after Evans and focusing on the calculus of variations, see Pomini 2018.

${ }^{22}$ Letter from Hotelling to Dresden, Dec. 11th, 1924 (HHP, Box 10, Folder 'AMS Reports and Correspondence (3)'). Hotelling's notes for the talk have also been preserved in the same folder.

${ }^{23}$ Monthly report from Hotelling to the directors of the Food Research Institute, Dec. 1st, 1924 (HHP, Box 41, Folder 'Agriculture III'). Hotelling talks about the calculus of variations as an "abstruse branch of mathematics" probably because his report was intended for supervisors who were neither mathematicians nor physicists.

${ }^{24}$ Evans mostly used the calculus of variations by considering demand functions as functions of current prices 
Drafts and notes dated 1925 show that, for a few months, Hotelling was struggling with the simplification of the analysis, but also with the definition of competition. His aim in 1925 was to "study by means of the same analysis monopoly and competition, usually theoretically treated as distinct problems, but actually shading gradually into each other" (HHP, Box 42, Folder 'Exploitation of Irreplaceable Assets'). The progressive (differentiated) exhaustion of resources of competing mines is a logical example of the continuity between monopoly and competition: competition may easily turn into oligopoly, duopoly or monopoly, if resources are progressively exhausted for this or that competitor. This led Hotelling to scrutinize duopoly situations (HHP, Box 42, Folder 'Exploitation of Irreplaceable Assets'). He made a presentation of his updated results in April 1925, during another AMS meeting in San Francisco. In the abstract of his talk entitled "Theory of Mine Economics" (1925b), he indicates that competition implies a "faster exploitation than alternatives" (monopoly?), but that this situation leads however to a maximum for the "public interest".

In all these early drafts and notes, many of the ideas, if not well established results, of the 1931 paper already existed: the basic formalisms of the question of rational exploitation of a mine in competition or in monopoly, as well as the search for the expression of the value of the mine; the use of Euler's equations to solve dynamic problems; the comparison of prices dynamics from the angle of the surplus' share between producers and consumers. All these elements we will find later in the 1931 paper therefore owe nothing to Ramsey's 1928 article. They however remained at the stage of scattered notes, for almost 4 years.

\subsection{Hotelling in England (1929)}

Hotelling stopped working on exhaustible resources for a while. His monthly reports to the directors of the FRI, as well as his working notes, indicate that other research fields became

and current inflation. In the 1931 article, Hotelling introduces such demand representations at the end of the paper (1931a, 162 and following). predominant in his agenda. In January 1926, he turned to the writing of an article on spatial competition. ${ }^{25}$ His research helped him to improve his knowledge of the economic literature, in particular Cournot, Bertrand and Edgeworth. And he developed his own theory of markets size and structure. ${ }^{26}$ On statistics, Hotelling pursued his work on the evaluation of statistical methods. After his reading of Keynes's Treatise on Probability, he found in the British statistician Ronald A. Fisher, the "Einstein of statistics", a major inspirer. $^{27}$

When Fisher published Statistical Methods for Research Workers (1925), he received skeptical comments. Hotelling was one of the few who appreciated the book, and made many efforts for its diffusion, in particular in the US (Hotelling 1927a; see Aldrich 2010, 120-121). Hotelling's articles on the generalization of the first law of Laplace (multi-correlations) (1926b) and on the general theory of stochastic problems (1927) were the first manifestations of what was about to represent the project of his life: to complete Fisher's work with robust mathematical foundations. From 1927b onwards, Hotelling and Fisher engaged an extensive correspondence, with deep theoretical discussions (Stigler 2007, 608). ${ }^{28}$

In the spring of 1929, Hotelling actively tried to raise funds for a 1-year trip in England. Commentators often notice that the objective of this trip was to meet and work with Fisher at the Rothamsted Experimental Station (Darnell 1990; Stigler 1999, 2007). ${ }^{29}$ Hotelling's unpublished correspondence however attests that the journey was also designed for other purposes. Not only Hotelling wanted to work with Fisher on the advancement of his statistical textbook, but he

\footnotetext{
${ }^{25}$ Before publication in the Economic Journal in 1929, a version was presented to the AMS in 1928.

${ }^{26}$ During the publishing process, Hotelling got in touch with Keynes, who also alerted him on Sraffa's on-going works (Darnell 1990, 14). Keynes' letter to Hotelling (dated Aug. 7th, 1928) is available both in Keynes papers (Cambridge University) and in Hotelling papers (HHP, Box 42, Folder 'Calculations Relating to: "Differential ..."').

${ }^{27}$ Letter from Hotelling to Van Sickle, April 22nd, 1929 (HHP, Box 1, Folder 'Van Sickle, John V.').

${ }^{28}$ Hotelling also tried to invite Fisher in Stanford in 192728, but faced administrative obstacles (Stigler 1999, 264).

${ }^{29}$ Fisher joined Rothamsted in 1919. See Mahalanobis 1964; Fisher Box 1978.
} 
also wanted to go to Britain to meet some particular economists, in order to have discussions on his mathematical economics projects. In a letter to the Head of the department at Stanford (dated April 22nd, 1929), Hotelling writes that he would like to meet Keynes, Ramsey and Bowley:

"In addition to this work on statistics, certain questions in pure economics would be illuminated by personal discussions with those who know most about them, a group including Keynes, Ramsey and Bowley." 30

In a letter to Fisher, dated April 28th, he explains himself with more details:

"I should also like to visit Cambridge and other School places, and to meet Wishart, Bowley, Keynes, the Biometric School people, F. P. Ramsey, and others. In addition to statistics I am much interested in mathematical economics, and would like to discuss various points, such as uses of the calculus of variations in economics and applications of the theory of seminvaraints (sic) and frequency curves to the determination of supply and demand functions, with the English economists whose work has come nearest to these subjects. ${ }^{\prime 1}$

The questions Hotelling intended to submit to these Englishmen were more precisely related to (1) "the economics of irreplaceable assets", (2) "the nature of supply and demands", (3) "joint supply and demand functions of related commodities" and (4) "applications of the calculus of variations" for the issue of stability in competition. ${ }^{32}$ Ramsey was sufficiently important in Hotelling's mind to be part of a short list of British economists to meet, and exhaustible resources were among the first questions needing exchanges with his colleagues.

With respect to our inquiry, this English trip episode implies several comments. First, whereas Hotelling seems to have been unaware

\footnotetext{
${ }^{30}$ Letter from Hotelling to Wildman, April 22nd, 1929 (HHP, Box 51, Folder 'Finances and Personal').

${ }^{31}$ Letter from Hotelling to Fisher, April 28th, 1929 (HHP, Box 14, Folder "IMS Draft for National Roster").

${ }^{32}$ Letter from Hotelling to Van Sickle, April 5th, 1929 (HHP, Box 1, Folder 'Van Sickle, John V.').
}

of Ramsey's work on subjective probability, in April 1929 he surely knew his work on saving (and taxation). ${ }^{33}$ It is therefore because of his research on this topic that Hotelling wanted to meet Ramsey. Second, we know that Hotelling finally did not succeed in financing a full year in England. ${ }^{34} \mathrm{He}$ went there only for a few months, from the end of June to the end of December 1929. At that time, Ramsey was in England, except in August 1929, enjoying a "walking tour of Ireland" (Paul 2012, 262). He however became ill in mid-November, and cancelled much of his activities (Paul 2012, 262). There is no evidence, in Hotelling's or Ramsey's archives, that the two men effectively met. Probably they did not.

Drafts on exhaustible resources appeared in Hotelling's notebooks again in November 1928, with a piece entitled "strong variation", and two pages of calculations in the appendix. A stock effect is introduced, with an important use of the calculus of variations. Other documents, dated 1929 , incorporate issues that were not treated in previous drafts: the determination of "the social value of a mine" (HHP, Box 42, Folder 'Exploitation of Irreplaceable Assets') and the consideration of the impact on collective welfare of the stock effect; the introduction of an excise tax on exhaustible resources in the case of a monopoly (HHP, Box 42, Folder 'Exploitation of Irreplaceable Assets'); and a 3-pages document, dated December 1929, presented as an abstract of a paper on the "exploitation of exhaustible assets" (HHP, Box 42, Folder 'Exploitation of Irreplaceable Assets'). We do not know if Ramsey has been the trigger of these latest developments, but they occurred after the publication of Ramsey's paper, and at the time of Hotelling's trip in England.

\footnotetext{
${ }^{33}$ From the 1920s onwards, Hotelling kept bibliographical notes on statistics and probability. None of Ramsey's works are mentioned in these notes. By contrast, Ramsey's 1928 paper on saving was reviewed by Hotelling for "Social science abstracts" (HHP, Box 25, Folder 'Causes of Birth Rate Fluctuations').

${ }^{34}$ Letter from Hotelling to Fisher, May 20th, 1929 (HHP, Box 14, Folder 'IMS Draft for National Roster').
} 


\subsection{The economics of exhaustible resources (1931)}

Hotelling finished "The Economics of Exhaustible Resources" in the second part of the year 1930. ${ }^{35}$ The published version in the Journal of Political Economy contains an introductory part staging the normative and political issues linked to the industry of exhaustible resources, with a hint at the Conservation movement controversies (Hotelling 1931a, 137-140). The main question that is treated is the determination of the optimal trajectory of ore extraction, according to different objectives (competition or monopoly profits, social value, etc.), and according to different competitive settings. Hotelling opts for an argumentative structure recalling Ramsey's article. He starts with a general rule, known as the Hotelling rule: $\mathrm{p}=\mathrm{p}_{0} \mathrm{e}^{\wedge} \gamma \mathrm{t}$ with $p$ for price, $t$ for time and $\gamma$ as the discounting factor (the market interest rate). ${ }^{36} \mathrm{He}$ then develops several theoretical case studies, with variations around this rule.

The rule is established for free competition (1931a, 140-146). Basically, Hotelling's principle is as follows: the resource will be extracted in order that the net price of the resource will rise at a rate equal to the interest rate, which is also the discount rate. Since a stock of ore constitutes a kind of capital for the producer, extracting resources is worth doing only if keeping them in beneath gives lesser future gains than selling them now in order to invest the sum on capital markets (with a return equal to the interest rate). ${ }^{37}$ Hotelling then explores monopoly situations, with linear or

\footnotetext{
${ }^{35}$ Two letters from Hotelling to Fisher and Chamberlin (dated July 23rd, 1930 and August 8th, 1930) indicate that he was working on the final version of the paper in the summer of 1930 (RAFP, digitized version online; Guicherd 2017, 179). A letter from Mills (dated Jan. 17th, 1931) shows that the final version already circulated at the very end of 1930 (HHP, Box 1, Folder 'Mills, Frederick C.').

${ }^{36}$ The expression "Hotelling rule" was popularized by Solow in 1974 in his article "The Economics of Resources or the Resources of Economics".

37 In fact, Hotelling's rule was not such a decisive innovation in the history of environmental economics. Lewis C. Gray $(1913,1914)$ and Gustav Cassel (1918) had already emphasized the same intuitive principle some years before (see Missemer 2017, chap. 4; Robinson 1989).
}

discontinuous paths of extraction (146-152). He introduces his stock-effect (152-164), and finally studies the role of public intervention (164-171) and the effect of oligopoly on prices (171-175).

Apart from his mathematical results, Hotelling questions the notion of intertemporal "public good" (1931a, 138), by looking at the implications of market structures: Should we prefer monopoly in order to preserve resources, but with "unduly high prices" (1931a, 138) for present consumers? Or should we opt for free competition, more in line with optimal collective welfare, but likely to deprive future generations of the resources? Hotelling provides information on these various questions, but does not take position.

This long narrative helps to characterize the Ramsey-Hotelling connection on the theoretical ground. An examination of the 1931 published paper in comparison with previous notes and drafts suggests that many ideas, tools and argumentative strategies were already in Hotelling's mind before the publication of Ramsey's paper on saving. This is particularly the case for the use of the calculus of variations, for his interest in dynamic issues (starting in the early 1920s), and for the 'case studies' rhetoric (already appearing in 1924-1925 drafts). Hotelling's explicit will to meet Ramsey during his 1929 England trip nevertheless indicates that he had a clear interest in his colleague's work. And some of the late developments for the 1931 paper could have found inspiration in Ramsey (e.g. the evaluation of the "social value of the mine" under private or public exploitation, taxation).$^{38}$ On the theoretical level, as well as on the interpersonal level (cf. the probable missed meeting between the two men in England in 1929), the Ramsey-Hotelling connection appears quite thin. Hotelling's view on dynamic issues had roots prior to Ramsey, and his inspirations

\footnotetext{
${ }^{38}$ Hotelling's interest in Ramsey's article was however partial, even on these points, since "total utility", "better called the social value of the resources" (1931a, 144) was not perceived, like in Ramsey, as the representation of the collective (or national) preferences. This total utility rather consisted of "concrete quantities, not symbols for pleasure" (145). This means that Hotelling's representation of social utility referred to consumers' surplus (through aggregate demand curves) rather than to a collective intertemporal utility function.
} 
were diverse; he was involved in other works as well (Hotelling 1929, 1932), under other influences. ${ }^{39}$ Yet other kinds of parallels require investigation.

\section{Searching for a background connection}

\subsection{The role of pure mathermatics}

The 1920s were a period of intellectual transition and reconstruction after the double shock that occurred at the beginning of the century: on the one hand, the crisis of physics, which showed that classical applied mathematics did not suit to up-to-date physics anymore, and that new tools (non Euclidian geometry, probability theory, matrices, topology) were needed $;{ }^{40}$ on the other hand, the foundation crisis of mathematics, which led to debates on how to reconstruct and unify mathematics. ${ }^{41}$ These crises opened more than two decades of high theory in mathematics and logic, with a flourishing literature in epistemology and controversies about scientific validation. In particular, at the heart of the debate was the role of mathematics (and what kind of mathematics) in constructing science.

In this environment, Ramsey and Hotelling developed independent but similar reactions. Both considered that pure mathematics should be separated from applied physics, and that an autonomous repertoire of mathematical tools composed of both old (including the calculus of variations) and new tools (probability, statistical theory, topology, etc.) - should be set up. Pure mathematics would therefore become the main resource for researchers involved in various disciplines, and would be the main lever for the

\footnotetext{
${ }^{39}$ For instance on taxation, his study of Edgeworth's paradox started in 1926 (HHP, Box 39, Folder 'Misc. (5)').

${ }^{40}$ For instance quantum theory challenged the habit of explaining the world with continuous and differentiable functions, and the theory of relativity called for rethinking the notions of space and time.

${ }^{41}$ Weintraub (2002, 9-10) retains three causes for this crisis: the difficult integration of non- Euclidian geometry; the failures of the set theory; and the paradoxes in the foundations of arithmetic and logic, associated with Frege and Peano. Russell's logicism was a response to these paradoxes. It was opposed to the formalist (Hilbert) and the intuitionist (Brouwer) refoundation programs. On these competing programs, see also Grattan-Guinness 2000.
}

progress of all sciences. Ramsey insisted on the role of mathematics to clarify, order and "selfcontrol" thoughts and scientific discourses (Ramsey 1991, 227). ${ }^{42}$ Hotelling also considered that mathematics might help to order thoughts, often "dissolved into many wordy pages" (Hotelling 1936, 163), not only in physics or economics, but also in biology, psychology and even literature. He regretted to see mathematics departments still inside the "schools of physical sciences" (1936, 157).

According to both authors, to make the diversity of available tools known and operational to young researchers, mathematics had to be taught in a new fashion. In 1922, when the Trinity Mathematical Society wondered about the opportunity to modify the program of the Tripos, Ramsey called for a rise of pure mathematics in the curriculum. ${ }^{43}$ And he defined himself as a "bad" teacher in preparing his students for the Tripos (Paul 2012, 188), because of his interest in explaining the fons et origo of the techniques and concepts rather than training students to twisted exercises. ${ }^{44}$ Hotelling shared

\footnotetext{
${ }^{42}$ Ramsey borrows the expression from Charles Sanders Peirce.

${ }^{43}$ Paul states $(2012,11)$ : “F. P. Ramsey said that applied mathematics had afforded no stimulus to advance since the middle of eighteenth century. All the recent advances in mathematical physics had been made by pure mathematicians. With regard to applied mathematics as a subject of study, he was of the opinion that it would be better to do away with it in the university, as it was merely a collection of standardized puzzles." The Tripos in mathematics was the core of final exams in Cambridge. The first part of the exam, common to all, basically consisted in Euclidian Geometry, arithmetic and classical tools of applied mechanics (restricted to static problems). Students' skills were tested through endless problems combining these methods. Weintraub (2002, chap. 1) shows how the Tripos in mathematics shaped the minds and the teaching of Cambridge's elites until the 1920s, making Cambridge science quite impervious to other kinds of mathematics.

${ }^{44}$ Reminding about Ramsey's lectures, Elphinson (1990, quoted by Paul 2012, 187) indicates: "In the 1920s, few schoolboys were taught this subject properly. Of course, we knew how to differentiate and understood the use of this operation of differentiation for discovering the properties and shapes of plane curves [...]. But in a very few schools was the subject dealt with in any sort of rigorous style. Ramsey introduced us to that magic number $e$ and to rigorous logical methods in analysis [...]. The differential geometry course showed me for the first time that we could really use them constructively to clarify a subject, rather than obscure it by treating it, in effect, as if in a foreign language".
} 
this opinion on the teaching of mathematics, as he wrote in his article published in 1936 in the The Mathematics Teacher:

"All this suggests that there is really quite a bit of mathematics to learn. [...] And the mathematics they study must not consist entirely of a lot of drill on multiplication and division. They can't put in all their time learning how to solve arithmetic problems that turn not on a knowledge of mathematics but on conventions, such as conventions about the width of wallpaper, and methods used for carpeting rooms. We have got to cut out a lot of those conventions $[\ldots]$, and put in their places some real knowledge of mathematics, higher mathematics, much more mathematics than has heretofore been thought necessary." (Hotelling 1936, 169)

Although Ramsey did not precisely write on the role of mathematics in economics, his reflection on "self-control" concerned all sciences, including applied fields (Ramsey 1991, 227). Hotelling went a little further, talking specifically about economics, arguing that mathematics was not only a support for statistics, but also contributed to the "very heart [...], the fundamental thing, economic theory" (1936, 163). Mathematics sheds light on the very assumptions required to rigorously prove economic believes, such as the efficiency of laissez-faire or the decreasing impact of taxation on demand. "Advanced calculus" and "modern algebraic developments" also lead to logical but counter-intuitive results that the intuition cannot see, "as in the case of taxation and exploitation of exhaustible resources" (164).

Ramsey and Hotelling did not use mathematics exactly in the same way in their respective inquiries into saving and exhaustible resources. Ramsey only tackled the calculus of variations $(1928,547)$, without extensive use (see Gaspard 2001, 2003, 421), probably to remain readable by Cambridge economists. In Hotelling, it is deeply exploited - a reminder that he started to work on mathematical economics for AMS conferences. Both authors however distinguished what could be grasped by "simple reasoning" (Ramsey 1928, 547) or "elementary methods" (Hotelling 1931a, 140) and what could not avoid the use of more complex tools - positive discount rate (Ramsey 1928, 547) and stock effect (Hotelling 1931a, 152).

In comparison with other mathematical economists of the previous generation (Walras, Marshall, Pareto, Fisher, and even in some sense Evans), Ramsey and Hotelling conceived mathematics as a necessary tool not because it was a synthetic language, or because of analogies with physics. It was necessary because of heuristics: it could provide unexpected insights, on condition that the researcher mobilizes the accurate tool in the general repertoire of pure mathematics, according to the problem addressed. Probably Ramsey and Hotelling were not the only ones in the 1920s1930s to share this conception. Some parallels could be expanded to other mathematical economists at the time. It is beyond the scope of this article to make this expansion, but it would be an interesting question for further research. ${ }^{45}$

With respect to the use of mathematics in general, Ramsey and Hotelling's perspective is not unlike G. H. Hardy's in his classic essay "A Mathematician's Apology" (1940), when he advocates the superiority of pure mathematics upon "trivial" tools (43) for the progress of science. ${ }^{46}$ Yet this rapprochement is only partial, because Hardy was skeptical about the implementation of pure mathematics in applied fields: "the mathematics [...] which can be used by economists or sociologist [sic] hardly rises to scholarship standard" (43). Obviously, Ramsey and Hotelling were more ambitious for social sciences, claiming the usefulness of pure

\footnotetext{
${ }^{45}$ Ramsey and Hotelling seem to have occupied a peculiar position in the period between the end of the nineteenth century, when economists looked for a "mechanical analogy" (Ingrao and Israel 1990) and "physical-modelbased analysis" (Weintraub 2002), and the middle of the twentieth century, when they opted for a "mathematical analogy" (Ingrao and Israel 1990) and "mathematicalmodel-based analysis" (Weintraub 2002). In a sense they were two pioneers of the "mathematical-model-based analysis", two decades before its development. The fact that Hotelling trained several major post-war economists (Arrow being a typical case) is a signal of this pioneering position. For extensive works on the history of mathematical economics, see also Israel 1996; Mirowski 1991.

${ }^{46}$ Hardy's essay was much discussed in the 1950 s and 1960 s, and occupies an important place in the history of mathematics in the middle of the twentieth century (see Mordell 1970).
} 
mathematics also for these fields. Their perspective exceeded one field in particular, to propose a global vision of mathematics for all sciences.

\subsection{Mathematics and normative issues: the design of economic policy}

In Ramsey and Hotelling's perspective, saving and exhaustible resources are issues deeply linked to public regulation. Should we tax saving? Should we limit the production of exhaustible resources, or even nationalize the mines? These questions are part of the argument; the connection between theory and policy is made through ethics. Ramsey discusses the consequences of the "ethically indefensible" (1928, 543) practice of discounting; Hotelling examines the "selfish" exploitation of natural resources (1931a, 137). These issues refer to intergenerational equity; but intra-generational equity is also at stake, through income distribution in the short-run. Ramsey's demonstration is supposed to answer Pigou's dilemma between encouraging saving and containing inequalities. Ramsey's inquiry is incomplete, but it nevertheless contains "interesting" normative results (Ramsey in Keynes 1983, 784) ${ }^{47}$ Hotelling's work presents a similar dilemma: if the regulation of extraction aims at preserving future generations' access to resources, monopoly is the best competitive design. It however distorts the sharing of the ongoing surplus; the "conservation" hypothesis may thus be accused to play the game of "those who are interested in maintaining high prices for the sake of their own pockets rather than of posterity" (1931a, 138). Hotelling's entire study (rule and variations) is supposed to provide a

\footnotetext{
${ }^{47}$ For instance, Ramsey's inquiry shows that the only way to reach "Bliss" and to maximize intertemporal national welfare is to apply the rule with no discount for future utilities and a planning framework. The introduction of a positive discount rate modifies the optimal path of saving, with a "modified Bliss" path (554), where national utility is lower than previously. Finally, in a decentralized economy, the existence of different discount rates leads to divergent familial trajectories inside the economy, condemning in particular families with a too high discount rate to eternal poverty (559). The existence of different discount rates thus generates inequalities of income and welfare in each generation.
}

map for escaping "two distinct evils, a Scylla and Charybdis between which public policy must be steered" (1931a, 138). ${ }^{48}$

In both Ramsey and Hotelling, public intervention is therefore linked to ethical dilemmas. One objective is to define a solid and enlightened basis for solving these dilemmas. Mathematics not only helps to clarify thought, but also participates to a sort of social engineering, to provide guidelines for public choice.

As mentioned, Ramsey came into scientific research with reformist views inspired by Guild socialism, with the conviction that mathematicians should use their skills to "improve the lot of [their] fellow men" (Ramsey 1923). His first goal in economic research was to inform public decision. In that sense, his contributions can be associated with the Cambridge research programs of the time, turned to the elaboration of the agenda and non-agenda of the State (see Keynes 1926). Ramsey aimed at defining the best way to collect taxes, and to regulate or organize capital accumulation, beyond the mere description of economic behaviors. ${ }^{49}$

This political and normative perspective, expressed in the 1928 article, was not missed by Hotelling when he read Ramsey: in his short bibliographical note prepared for Social Science Abstracts, he underlines that "one of several striking conclusions is that in the accounting of a Socialist State the function of the rate of interest would be to ensure the wisest use of existing capital, not to serve in any direct way as a guide to the proportion of income which should be saved" (Hotelling 1931b, 1). Hotelling was thus sensitive to Ramsey's

\footnotetext{
${ }^{48}$ Hotelling establishes that a private monopoly would be the appropriate structure for the conservation of resources, but that competition would bring a higher intertemporal "surplus". A public monopoly - or "a benevolent and allwise state" (Hotelling 1936, 166) - targeting the "total utility" or "social value of the resource" $(1931,143)$ would adopt the same schedule of exploitation as producers under (perfect) competition, shortening the exhaustion time. An unexpected tax on the private monopoly rent, or a severance tax on private monopoly could both slow exploitation and lower prices.

${ }^{49}$ Paul (2012) indicates that "[Ramsey] was interested in using economics as a tool for reform rather as a way of explaining why things are as they are" (260).
} 
ambitions with public decisions.

In the 1920s, Hotelling's contributions turned from practical optimization programs (the optimization of the life of a machine) to a global analysis of competition regulation (Hotelling 1929) and of the organization of public ownership, public investment and taxation when competition fails to bring optimal welfare (Hotelling 1932, 1938). Reconstructing his economic agenda means to insist on policyoriented studies. Like in Ramsey, Hotelling's research was not applied economics strictly speaking, rather theoretical contributions designed to give new information to economic agents to help them to take decisions. This perspective clearly appears in the 1931 article. Hotelling does not provide normative indications on resources management, but states that this or that competition structure, this or that optimization criterion, will lead to this or that result in terms of social welfare and resources preservation. This is a different attitude from his predecessor Gray, whom objective was to "point out the economic possibilities of conservation" (1913, 499). Hotelling does not take position in the conservation debates; he simply shows interest in the clarification of these debates through robust results coming from pure mathematics. There is a convergence with Ramsey on this point: the interest of the two authors is not in economic theory for the sake of it, but for the progress of science to help people, including the State, to make well informed decisions.

In summary, in the wake of the crises of physics and mathematics, Ramsey and Hotelling built similar intellectual projects, with a pure mathematical research base - probability and logic for Ramsey, topology and statistical theory for Hotelling - to complete a toolkit, then exploited on specific issues, including economic problems. The ambition was to produce new results that could not be reached with usual methods (literary reasoning, descriptive statistics, etc.), to participate to the progress of science and to help public decision. The uniqueness of this perspective would deserve further investigation, since other scholars, even inside economics, seem to have pursued the same kind of project (e.g. Jan Tinbergen, see Boumans 1993). Our result is however that
Ramsey and Hotelling shared a common vision of the heuristics of mathematics, and that their connection is probably less known and more intense on this point than on the theoretical or interpersonal levels.

\section{Conclusion}

Frank P. Ramsey and Harold Hotelling are considered as two pioneering authors in the field of intertemporal decision theory. Because they used similar tools, were interested in dynamic issues, and because Hotelling cited Ramsey, the secondary literature often makes a quick link between the two authors, even talking about a "Ramsey-Hotelling connection". We felt the need to question this link, to characterize it, in order to contribute to this literature, and to better understand Ramsey's and Hotelling's intellectual projects.

We found that in terms of direct connection, Ramsey's and Hotelling's works failed to meet: probably Ramsey did not hear about Hotelling; and even if Hotelling knew Ramsey's 1928 paper, and even if the chronology of his research on exhaustible resources leaves open some potential points of influence, most of his ideas, intuitions and tools were in his mind before the publication of Ramsey's paper. Their missed 1929 rendezvous in England is an anecdotal indicator that their direct interpersonal and theoretical connection remained thin.

Yet this does not mean that the RamseyHotelling connection is meaningless. The parallel trajectories of the two men, and their common perspective on pure mathematics, science and public decision shed light on a background relation deserving interest. Ramsey and Hotelling proposed similar answers to the crisis of physics and mathematics, by insisting on the necessity to set up an independent repertoire of pure mathematical tools offering new means of research in all sciences, including economics. In their respective papers on saving and exhaustible resources, they tried to inform economic and political choices, by exploring different futures resulting from various individual or public decisions (zero vs. positive discount rates, centralized vs. decentralized economy, private vs. social earnings of ore 
extraction, monopoly vs. competition, etc.).

The Ramsey-Hotelling connection is not only a matter of citation or of precocious use of the calculus of variations in economics; it is also a matter of intellectual project and of vision of pure mathematics for research and policy. ${ }^{50}$ Their works failed to find a large audience in the 1930s and 1940s. Economists probably were not ready to embrace the technical developments and the trust in mathematics for examining the moral and political implications of economic decisions. This does not mean that Ramsey and Hotelling played no role in the $1930 \mathrm{~s} .{ }^{51}$ In particular, Hotelling continuously taught mathematical economics at Columbia University at the time. He trained, episodically or for a longer period of time, some major figures of post-war economic dynamics (Arrow, Debreu, Dorfman, Koopmans, Samuelson, etc.). A continuation of our research would be to investigate to what extent the seeds Ramsey and Hotelling sowed, at the turn of the 1930s, shaped post-war economics, not only from a theoretical but also from a methodological point of view.

\section{Acknowledgements}

This paper benefited from the support of the European Society for the History of Economic Thought (ESHET), through the project 'Bifurcations in Natural Resource Economics (1920s-1930s)'. We thank R. Ferreira da Cunha, M. P. V. Franco, T. M. Mueller and F. Nadaud for stimulating discussions in the workinggroup. Thanks also to the participants in the 2016 ESHET Conference in Paris and in the 2018 Environmental Economics Conference in

\footnotetext{
${ }^{50}$ The fact that the calculus of variations was not the most important feature of the Ramsey-Hotelling connection is reinforced by the existence of another tradition after Evans, with Charles Roos and some Italian scholars (Amoroso, La Volpe), which precisely focused on the calculus of variations in the 1920s, 1930s and 1940s (see Pomini 2018).

${ }^{51}$ Duarte (2009b) explains that Ramsey's 1928 article was known in the 1930s, even if it failed to find a large readership until economists were ready to associate "mathematical formalism, utility maximizing agents and aggregate level control". Hotelling was sometimes cited in the 1930s (Hart 1937; Smithies 1939), even if major developments came later (e.g. Gaffney 1967).
}

Orléans, and to the readers of previous versions of this paper. We are grateful to the staff of the Rare Book and Manuscript Library of Columbia University for their help during our archival visit in Hotelling papers, and to the staff of the Special Collections Library of the University of Adelaide. We finally thank the reviewers for their suggestions to improve the paper.

\section{Archives}

FPRP: Frank P. Ramsey Papers, Archives and Special Collections, University of Pittsburgh, USA. Catalogue:

https://www.library.pitt.edu/archives-specialcollections

HHP: Harold Hotelling Papers, Rare Book and Manuscript Library, Columbia University, USA. Catalogue:

http://findingaids.cul.columbia.edu/ead/nnc-rb/ ldpd_4078401

JMKP: John Maynard Keynes Papers, King's College Archive Centre, Cambridge University, UK. Catalogue: https://janus.lib.cam.ac.uk/db/node. Xsp?id1/4EAD/GBR/0272/PP/JMK

RAFP: Ronald A. Fisher Papers, Special Collections Library, University of Adelaide, Australia. Catalogue:

https://digital.library.adelaide.edu.au/dspace/han dle/2440/3860.

\section{References}

Aldrich, J. 2010. "The Econometricians' Statisticians, 1895-1945." History of Political Economy 42 (1): 111-154.

Arrow, K. J. 1974. "In Memoriam: Harold Hotelling, 1895-1973." American Economic Review 64 (6): 1102-1103.

Arrow, K. J. 1980. "Review of 'Foundations: Essays in Philosophy, Logic, Mathematics and 
Economics', by F. P. Ramsey, edited by D. H. Mellor." Journal of Political Economy 88 (3): 636-638.

Arrow, K. J. 1987. Hotelling, Harold. In The New Palgrave. A Dictionary of Economics, Vol. 2, edited by J. Eatwell, M. Milgate, and P. Newman, 670-671. London, Basingstoke, New York \& Tokyo: MacMillan.

Arrow, K. J. 2009. "Some Developments in Economic Theory since 1940: An Eyewitness Account." Annual Review of Economics 1 (1): 116.

Arrow, K. J., and M. Kurz. 1970. "Optimal Growth with Irreversible Investment in a Ramsey Model.” Econometrica 38 (2): 331-344.

Attanasio, O. P. 2015. "Frank Ramsey's Mathematical Theory of Saving." Economic Journal 125 (583): 269-294.

Bolza, O. 1904. Lectures on the Calculus of Variations. Chicago: University of Chicago Press.

Boumans, M. 1993. "Paul Ehrenfest and Jan Tinbergen: A Case of Limited Physics Transfer. In: N. de Marchi (ed.), Non-Natural Social Science: Reflecting on the Enterprise of 'More Heat than Light." History of Political Economy 25 (suppl_1): 131-156.

Bromley, D. W. S. 2008. The New Palgrave Dictionary of Economics. 2nd edition, edited by S. N. Durlauf and L.E. Blume. Basingstoke: Palgrave Macmillan,

Cassel, G. 1918. [1932]. The theory of social economy. English translation by S. L. Barron, 5th edition [1967]. New York: Augustus M. Kelley.

Collard, D. 1996. "Pigou and Future Generations." Cambridge Journal of Economics 20 (5): 585-597.

Crabbé, P. J. 1986. "Gray and Hotelling: A Reply." Journal of Environmental Economics and Management 13 (3): 295-300.
Darnell, A. C. 1988. "Harold Hotelling 18951973.” Statistical Science 3 (1): 57-62.

Darnell, A. C. 1990. "The Life and Economic Thought of Harold Hotelling." In The Collected Economics Articles of Harold Hotelling, edited by A. C. Darnell, 1-28. New York: SpringerVerlag.

Duarte, P. G. 2009. "Frank P. Ramsey: A Cambridge Economist." History of Political Economy 41 (3): 445-470.

Duarte, P. G. 2009. “The Growing of Ramsey's Growth Model." History of Political Economy 41 (Suppl 1): 161-181.

Duarte, P. G. 2016. "Frank Ramsey." In The Palgrave Companion to Cambridge Economics, edited by R. Cord, 649-671. London: Palgrave MacMillan.

Erreygers, G. 2009. "Hotelling, Rawls, Solow: How Exhaustible Resources Came to Be Integrated into the Neoclassical Growth Model." History of Political Economy 41 (Suppl 1): 263181.

Evans, G. C. 1922. "A Simple Theory of Competition." American Mathematical Monthly 29 (10): 371-380.

Evans, G. C. 1924. "The Dynamics of Monopoly." American Mathematical Monthly 31 (2): 77-83.

Evans, G. C. 1925. "Economics and the Calculus of Variations." Proceedings of the National Academy of Science 11 (1): 90-95.

Fisher, R. A. 1925. Statistical Methods for Research Workers. Edinburgh: Oliver \& Boyd.

Fisher Box, J. 1978. R. A. Fisher, the Life of a Scientist. New York: Wiley \& Sons.

Gaffney, M., ed. 1967. Extractive Resources and Taxation. Madison, Milwaukee \& London: University of Wisconsin Press. 
Gans, J. S., and G. B. Shepherd. 1994. "How Are the Mighty Fallen: Rejected Classic Articles by Leading Economists." Journal of Economic Perspectives 8 (1): $165-179$.

Gaspard, M. 2001. "Les Démonstrations de la Règle de Ramsey: les Mathématiques Comme 'self-Control." Revue économique 52 (3): 595604.

Gaspard, M. 2003. "Ramsey's Theory of National Saving: A Mathematician in Cambridge." Journal of the History of Economic Thought 25 (4): 413-435.

Gaspard, M. 2005. "Individual Behaviors and Collective Welfare: Ramsey's

"microfoundations" of "macro-equilibrium". Conference on the history of macroeconomics, Louvain la Neuve, Belgium.

Gaspard, M. 2014. "Logic, Rationality and Knowledge in Ramsey's Thought: Reassessing 'Human Logic." Journal of Economic Methodology 21 (2): 139-157.

Goldstine, H. H. 1980. A History of the Calculus of Variations from the 17th Through the 19th Century. New York: Springer.

Grattan-Guinness, I. 2000. The Search for Mathematical Roots, 1870-1940; Logics, Set Theories and the Foundations of Mathematics from Cantor Through Russell to Gödel. Princeton: Princeton University Press.

Guicherd, T. 2017. "Essai sur la genèse de la théorie de la concurrence monopolistique d'Edward H. Chamberlin; Entre histoire subjective et reformulation d'une théorie." $\mathrm{PhD}$ Thesis, Université Lumière Lyon 2.

Gray, L. C. 1913. "The Economic Possibilities of Conservation." Quarterly Journal of Economics 27 (3): 497-519.

Gray, L. C. 1914. "Rent under the Assumption of Exhaustibility." Quarterly Journal of Economics 28 (3): 466-489.
Hadamard, J. 1910. Leçons sur le calcul des variations. Paris: Hermann \& fils.

Hancock, H. 1904. Lectures on the calculus of variations. Cincinnati: Cincinnati University Press.

Hardy, G. H. 1940. [2005]. A Mathematician's Apology. Edmonton: University of Alberta Mathematical Sciences Society. Electronic version.

Hart, A. G. 1937. "Business Planning, and the Cycle." Quarterly Journal of Economics 51 (2): 273-297.

Hilbert, D. 1900. "Matematische Probleme." Göttinger Nachrichten 1900: 253-297.

Hotelling, H. 1925. "A General Mathematical Theory of Depreciation." Journal of the American Statistical Association 20 (151): 340353.

Hotelling, H. 1925b. "Theory of Mine Economics." Bulletin of the American Mathematical Society 31: 389. [abstract only].

Hotelling, H. 1925. "Three-Dimensional Manifolds of States of Motion." Transactions of the American Mathematical Society 27 (3): 329344.

Hotelling, H. 1925. "The Distribution of Correlation Ratios Calculated from Random Data." Proceeding of the National Academy of Science 11 (10):657-662.

Hotelling, H. 1926a. "Multiple-Sheeted Spaces and Manifolds of States of Motion." Transactions of the American Mathematical Society 38: 479-490.

Hotelling, H. 1926b. "Two Generalisations of the Pearsonian Correlation Coefficient." Bulletin of the American Mathematical Society 32: 98.

Hotelling, H. 1927a. "Differential Equations Subject to Error, and Population Estimates." Journal of the American Statistical Association 22 (159): 283-314. 
Hotelling, H. 1927b. "Review of 'Statistical Methods for Research Workers', by R. A. Fisher." Journal of the American Statistical Association 22 (159): 411-412.

Hotelling, H. 1929. "Stability in Competition." Economic Journal 39 (153): 41-57.

Hotelling, H. 1931a. "The Economics of Exhaustible Resources." Journal of Political Economy 39 (2): 137-175.

Hotelling, H. 1931b. Ramsey, F.P./A Mathematical Theory of Saving. Note prepared for Social Science Abstracts. HHP, Box 25, Folder 'Causes of Birth Rate Fluctuations'.

Hotelling, H. 1932. "Edgeworth's Taxation Paradox and the Nature of Demand and Supply Function." Journal of Political Economy 40 (5): 577-616.

Hotelling, H. 1936. "Little Known Applications of Mathematics." The Mathematics Teacher 29 (4): 157-169.

Hotelling, H. 1938. "The General Welfare in Relation to Problems of Taxation and of Railway and Utility Rates." Econometrica 6 (3): 242269.

Hotelling, H. 1948. Western Hotelling and Allied Families. An Epic of Migration. HHP, Box 52.

Hotelling, H. 1963. Autobiographical remarks. Honorary degree acceptance speech.

Inauguration of W. Allen Wallis as president, 16 May 1963, University of Rochester, transcript from a tape recording, not corrected or edited, $5 \mathrm{p}$.

Ingrao, B., and G. Israel. 1990. The Invisible Hand: Economic Equilibrium in the History of Science. Cambridge, MA: The MIT Press.

Israel, G. 1996. La mathématisation du réel: Essai sur la modélisation mathématique. Paris: Seuil.
Kamien, M. I. 1987. "Calculus of Variations.” In The New Palgrave. A Dictionary of Economics, vol. 1, edited by J. Eatwell, M. Milgate, and P. Newman, 312-313. London, Basingstoke, New York \& Tokyo: MacMillan.

Kamien, M. I., and N. L. Schwartz. 1991. Dynamic Optimization. The Calculus of Variations and Optimal Control in Economics and Management. 2nd ed. Amsterdam and New York: North-Holland (Advanced Textbooks in Economics).

Keynes, J. M. 1926. The End of Laissez-Faire. London: Hogarth Press.

Keynes, J. M. 1983. Economic Articles and Correspondences: Investment and Editorial, Collected Writings of John Maynard Keynes. Vol. XII. London: Macmillan.

Kneser, A. 1900. Lehrbuch der varationsrechnung. Vieweg: Braunschweig.

Kula, E. (1996). "Social Project Appraisal and Historical Development of Ideas on Discounting - A Legacy for the 1990s and Beyond." In Cost-benefit Analysis and Project Appraisal in Developing Countries, edited by C. Kirkpatrick and J. Weiss, 75-89. Cheltenham \& Brookfield: Edward Elgar Publishing.

Levene, H. 1974. "Harold Hotelling, $1895-$ 1973." The American Statistician 28 (2): 71-73.

Mahalanobis, P. C. 1964. "Professor Ronald Aylmer Fisher." Biometrics 20 (2): 238-252.

Mayer, A. 1905. “Über Den Hilbertschen Unäbhangigkeitsatz in Der Theorie Des Maximums Und Minimums Der Einfachen Integrale.” Ber. Verh. Ges. Wiss Leipzig 57: 4967.

Mellor, D. H. 1990. Introduction. In Philosophical Papers, edited by D. H. Mellor, xi-xxv. Cambridge, UK: Cambridge University Press.

Michel, P. 1990. "Some Clarifications on the Transversality Condition." Econometrica 58 (3): 
$705-723$.

Mirowski, P. 1991. More Heat Than Light. Economics as Social Physics, Physics as nature's economics. Cambridge, UK: Cambridge University Press.

Missemer, A. 2017. Les Économistes et la fin des énergies fossiles (1865-1931). Paris: Classiques Garnier.

Mordell, L. 1970. "Hardy's “A Mathematician's Apology." The American Mathematical Monthly 77 (8): 831-836.

Morrey, C. B. 1983. Griffith Conrad Evans, 1887-1973, A Biographical Memoir.

Washington, DC: National Academy of Science.

Paul, M. 2012. Frank Ramsey (1903-1930), a Sister's Memoir. Huntingdon: Smith Gordon.

Pigou, A. C. 1920. The economics of welfare. $1 \mathrm{st}$ ed. London: Macmillan.

Pomini, M. 2018. "Economic Dynamics and the Calculus of Variations in the Interwar Period." Journal of the History of Economic Thought 40 (1): 57-79.

Ramsey, A. S. 1913. A Treatise on Hydromechanics: Hydrodynamics. London: Bell $\&$ Sons.

Ramsey, F. P. 1922. "The Douglas Proposals.” The Cambridge Magazine 11 (1): 74-76.

Ramsey, F. P. 1923. "Socialism and Equality of Income, Papers for the Cambridge Discussion Society". In Notes on Philosophy, Probability and Mathematics, edited by M. C. Galavotti, 313-319. Naples: Bibliopolis-Edizioni di Filosofia e Scienze.

Ramsey, F. P. 1925a. The Foundations of Mathematics. In Philosophical Papers, edited by D. H. Mellor, 164-224. Cambridge, UK: Cambridge University Press.

Ramsey, F. P. 1925b. Universals. In Philosophical Papers, edited by D. H. Mellor,
8-33. Cambridge, UK: Cambridge University Press.

Ramsey, F. P. 1926a. Mathematical Logic. In Philosophical Papers, edited by D. H. Mellor, 225-244. Cambridge, UK: Cambridge University Press.

Ramsey, F. P. 1926b. Truth and Probability. In Philosophical Papers, edited by D. H. Mellor, 52-94. Cambridge, UK: Cambridge University Press.

Ramsey, F. P. 1927a. Facts and Propositions. In Philosophical Papers, edited by D. H. Mellor, 34-51. Cambridge, UK: Cambridge University Press.

Ramsey, F. P. 1927b. "A Contribution to the Theory of Taxation." Economic Journal 37 (145): 47-61.

Ramsey, F. P. 1928. "A Mathematical Theory of Saving.” Economic Journal 38 (152): 543-559.

Ramsey, F. P. 1929a. Theories. In Philosophical Papers, edited by D. H. Mellor, 112-136.

Cambridge, UK: Cambridge University Press.

Ramsey, F. P. 1929b. General propositions and causality. In Philosophical Papers, edited by D. H. Mellor, 145-163. Cambridge, UK:

Cambridge University Press.

Ramsey, F. P. 1991. Notes on Philosophy, Probability and Mathematics, edited by M. C. Galavotti, Naples, Bibliopolis-Edizioni di Filosofia e Scienze.

Ramsey, F. P. 2009. "Frank Ramsey's Notes on Saving and Taxation". In History of Political Economy. Vol 41, edited by P. G. Duarte, 471489.

Read, C. 2016. The econometricians: Gauss, Galton, Pearson, Fisher, Hotelling, Cowles, Frisch and Haavelmo. London: Palgrave MacMillan UK.

Robinson, T. J. C. 1989. Economic Theories of Exhaustible Resources. London \& New York: 
Routledge.

Russell, B. 1903. The Principles of Mathematics. Cambridge, UK: Cambridge University Press.

Russell, B., and A. Whitehead. 1910. [1953].

Principia Mathematica. Cambridge, UK:

Cambridge University Press.

Russell, B. 1914. Our Knowledge of the External World. London: George Allen \& Unwin.

Sahlin, N. E. 1990. The Philosophy of F. P. Ramsey. Cambridge, UK: Cambridge University Press.

Samuelson, P. 1960. "Harold Hotelling as Mathematical Economist." The American Statistician 14 (3): 21-25.

Smith, W. L. 1978. "Harold Hotelling 18951973." The Annals of Statistics 6 (6): 11731183.

Smithies, A. 1939. "The Maximization of Profits over Time with Changing Cost and Demand Functions." Econometrica 7 (4): 312-318.

Solow, R. 1974. "The Economics of Resources or the Resources of Economics." American Economic Review 64 (2): 1-14.

Stigler, S. M. 1999. "The Foundations of Statistics at Stanford." The American Statistician 53 (3): 263-266.

Stigler, S. M. 2007. "The Epic Story of Maximum Likelihood." Statistical Science 22 (4): 598-620.

Taylor, G. 2006. Frank Ramsey: A Biographical Sketch. In Cambridge and Vienna: Frank Ramsey and the Vienna Circle, edited by M. C. Galavotti, 1-18. Dordrecht: Springer.

Taylor, J. S. 1923. "A Statistical Theory of Depreciation Based on Unit Cost." Journal of the American Statistical Association 18: 10101023.

Weintraub, E. R. 2002. How Economics Became a Mathematical Science. Durham \& London: Duke University Press.

Weitzman, M. 2003. Income, Wealth, and the maximum principle. Cambridge, MA: Harvard University Press.

Wittgenstein, L. 1922. Tractatus LogicoPhilosophicus. Translated by C.K. Ogden. London: Routledge. 